\title{
ESTUDI DE LES VARIABLES SEXE, EDAT I NOTA MITJANA SOBRE LA COMPETÈNCIA SOCIAL, EN ESTUDIANTS DE SECUNDÀRIA
}

\author{
ESTUDIO DE LAS VARIABLES SEXO, EDAD Y NOTA MEDIA \\ SOBRE LA COMPETENCIA SOCIAL, \\ EN ESTUDIANTES DE SECUNDARIA
}

STUDY OF THE VARIABLES GENDER, AGE AND AVERAGE

SCORE ON THE SOCIAL COMPETENCE, IN SECONDARY STUDENTS

\author{
Sara Lorente Escriche* \\ Manuel Martí-Vilar ${ }^{* *}$, Núria Melià Martín ${ }^{* * *}$
}

DOI: 10.7203/anuari.psicologia.17.2.31

\begin{abstract}
Resum
S'analitza la influència que variables independents com el sexe, l'edat i la nota mitjana exerceixen sobre la Competència Social dels adolescents, a més d'una breu aproximació teòrica a aquest constructe. La mostra es compon de 193 estudiants d'Ensenyament Secundari Obligatori, compresos entre els 12 i els 16 anys. S'ha emprat l'instrument d'avaluació de la Competència Social de Matson i al. (MESSY, 1983). Ha estat en l'escala d'Habilitats Socials Apropiades, on els adolescents han obtingut majors puntuacions i es confirma la influència de les tres variables anteriors sobre la Competència Social.

Paraules clau: Competència Social, adolescents, sexe, edat.

* Professora de la Universidad de Zaragoza. Facultat d'Humanitats i Ciències Socials. Departament de Psicologia i Sociologia. Docent en el Col·legi Victoria Díez (Terol).

** Professor Titular, Departament de Psicologia Bàsica, Universitat de València. Línia d'investigació: Pensament i Interacció Social.E-mail: <Manuel.Marti-Vilar@uv.es>.

**** Psicòloga. Universitat de València. Membre del Col·legi de Psicòlegs de la Comu-
\end{abstract} E-mail: <slorente@unizar.es>. nitat Valenciana. E-mail: <nurmm.1989@gmail.com>. 


\title{
Resumen
}

Se analiza la influencia que variables independientes como el sexo, la edad y la nota media ejercen sobre la Competencia Social de los adolescentes y una breve aproximación teórica a este constructo. La muestra se compone de 193 alumnos de entre 12 y 16 años que estudian Educación Secundaria Obligatoria. Se ha utilizado el instrumento de evaluación de la Competencia Social de Matson i al. (MESSY, 1983). Es en la escala de Habilidades Sociales Apropiadas donde los adolescentes han obtenido mayor puntuaciones y se confirma la influencia de las tres variables en la Competencia Social.

Palabras clave: Competencia Social, adolescentes, sexo, edad.

\begin{abstract}
The influence of independent variables like gender, age and average score on the Social Competence of teenagers and a brief theoretical approach to that concept will be analyzed on this paper. The sample of the study is formed by 193 pupils between 12 and 16 years old who study Compulsory Secondary Education. The instrument to evaluate the Social Competence of Matson i al. (MESSY, 1983) has been used.The teenagers of the sample have obtained the highest scores in the scale of Appropriate Social Skills and the influence of the former three variables in Social Competence is confirmed.
\end{abstract}

Key words: Social Competence, teenagers, gender, age.

\section{Introducció}

En la societat actual de la informació i el coneixement, on les relacions humanes vénen marcades pel dinamisme i les noves tecnologies, s'ha aconseguit retallar distàncies quant a la comunicació interpersonal. No obstant això, paradòxicament, les relacions personals suposen un repte per a molts hómens i dones que s'enfronten a les pròpies dificultats de relació. Les persones es construeixen arran el contacte amb altres persones, la qual cosa fa necessari disposar de les competències socials adequades que en permetés una interacció adequada i ajustada. Tal com recull Lorente (2014), sense la capacitat d'establir contacte humà no s'és capaç de superar les demandes que exigeixen els distints contextos socials.

La Competència Social, tan necessària per a la comunicació i socialització, ha estat descuidada des de diversos àmbits, entre què s'inclou l'escolar. L'escola continua mantenint el seu paper com a transmissor del coneixement, i oblida en molts moments la dimensió psicoeducativa de la Comprensió Social 
i la seua rellevància per al desenvolupament integral de la persona. És en l'adolescència quan els joves entren en un món en què aquestes relacions interpersonals apleguen inclús a estremir, però a través del desenvolupament de la pròpia Competència Social és possible pensar en uns joves capaços de relacionar-se socialment $\mathrm{i}$ en totes les millores que hi poden suposar en les seues vides.

Per aquest motiu, la finalitat del present estudi radica en analitzar les variables que poden influir en la Competència Social, com ara el sexe, l'edat i la nota mitjana. Després de conéixer aquestes variables, el més oportú seria mobilitzar les accions adequades dirigides a previndre els problemes que se'n poden derivar de les dificultats del seu ajustament.

S'hi constitueix un estudi mitjançant l'aplicació de l'instrument d'avaluació de la Competència Social de Matson, Rotatori i Helsel (1983), anomenat Matson Evaluation of Social Skills in Youngsters (MESSY) a estudiants d'Educació Secundària Obligatòria, i en què s'establiran diferències relacionades amb les tres variables esmentades anteriorment.

L'avaluació s'ha dut a terme d'una manera independent i en un únic moment temporal. S'ha emprat l'estratègia de realitzar una avaluació que atén al grup-criteri, la qual cosa suposa una anàlisi estadística de puntuacions mitjançant l'agrupació de l'alumnat en funció de les variables que s'han especificat en distints apartats anteriors. L'estudi, doncs, s'ha desenvolupat a partir de les dades obtingudes de les anàlisis ANOVAs. Per a açò, s'han pres les variables dependents $i$ independents i s'ha observat l'existència de diferències estadísticament significatives entre els diferents grups segons els plantejaments teòrics previs.

\section{Gènesi de l'estudi de la Competència Social}

Des d'una perspectiva històrica de la Competència Social, han estat diversos els autors qui paulatinament han configurat el corpus de teoria i pràctica envers aquest constructe.

Els estudis relacionats amb aquest tema durant els anys 30 estaven especialitzats en la conducta socials dels xiquets i la mesura sociomètrica, mentre que als anys 60 es produeix un canvi i la tendència gira al voltant de l'estudi de la Competència Social des d'un prisma clínic i terapèutic.

L'estudi de la Competència Social va tindre distintes fonts que el van constituir, tal i com estableix Padés (2003, 2010; Lorente, 2014). En primer lloc, Salter (1949), en al seu llibre Conditioned Reflex Therapy -Teràpia dels Reflexos Condicionats-, empra per primer cop el terme «personalitat excitatòria», definida com a la capacitat de l'individu per a expressar les pròpies emocions. Aquests estudis van estar continuats per Wolpe (1977), qui va ser pioner en referir al concepte de «conducta assertiva» com a l'expressió adequada dirigida cap a altra persona de qualsevol emoció que no siga la resposta d'ansietat. 
Segons Padés (2003, 2010), altres fonaments històrics en l'estudi de la Competència Social apareixen als Estats Units, on en basaven les investigacions en les teràpies de modificació de conducta, en què s'atribueix l'interès de la Competència Social a l'estudi de les variables situacionals. En contraposició a açò últim, els estudis europeus han estat dirigits cap a la influència de les conductes no verbals presents en la interacció social. Per la seua banda, en Regne Unit s'empra per primera volta el terme «habilitat» i es considera l'analogia home-màquina. En aquest marc es pot situar a Argyle $(1967,1969)$ i a Argyle i Kendon (1967).

Serà a partir de la dècada dels 80 quan la Competència Social es considera des d'una perspectiva educativa, moment en què se superen les concepcions tradicionals de la «rehabilitació» i se'n destaca la importància de la prevenció. Més tard, als anys 90, es produiria un augment de les investigacions en aquest camp, on els sentiments es converteixen en l'eix fonamental del desenvolupament sociopersonal. D'aquesta manera, la Competència Social implica considerar les variables cognitives, afectives i conductuals, a més dels contextos de socialització en què la persona es desenrotlla.

\section{Delimitació conceptual}

En revisar la literatura referent a la Competència Social, s'hi planteja una dificultat terminològica, arran la referència que se'n fa amb distints vocables en funció dels enfocaments des què s'aborda. No obstant, en tots ells apareix recollida com un procés interactiu que requereix unes competències i habilitats de la persona per què es desenvolupe socialment i siga capaç de fer front a les demandes del context.

Cal considerar que en l'estudi del concepte «Competència Social», la literatura hi sol fer referència a l'eficàcia de l'execució dels comportaments socials, però també apareix com a sinònim d'aquest el terme «habilitat social» (Benítez i al., 2011) que tendeix a aplicar-se a les capacitats específiques que es requereixen en el seu desenvolupament. Des d'aquest estudi, es consideraran com a equivalents.

Padés $(2003,2010)$ recull la definició d'una conducta socialment habilidosa de Gismero (2000):

el conjunt de respostes verbals i no verbals, particularment independents i situacionalment específiques, a través de les quals un individu expressa en un context interpersonal les seues necessitats, sentiments, preferències, opinions o drets sense ansietat excessiva i de manera no aversiva, amb respecte cap a la resta, que duu com a consequiència l'auto-reforçament i maximitza la probabilitat d'aconseguir un reforçament extern. 
La Competència Social fa referència a les habilitats que posseeix una persona que li permeten superar situacions de conflicte tant en l'àmbit professional com en el personal. Per a Topping, Bremner i Holmes (2000), i Daniel i Rojas (2012), el concepte de Competència Social consisteix a tindre i emprar una habilitat per integrar tant el pensament com el comportament, per a, d'aquest mode, abastar l'èxit en les pròpies manifestacions socials dins un context cultural determinat. A més, com recullen Gilar, Miñao i Castejón (2008):

La Competència Social no és un atribut homogeni, sinó una constel·lació de pensaments, habilitats i comportaments que varien d'una situació a altra.

Aquests autors recopilen, a més, de Topping i al. (2000) la idea de què açò aplicat al context escolar hauria considerar que els comportaments esmentats suposarien:

l'accés amb èxit al currículum escolar, associar les necessitats personals i socials, i el desenvolupament d'habilitats i actituds transferibles més enllà de l'escola.

A més, es pot exemplificar amb una afirmació que diu que

els xiquets que generalment no cauen bé als seus companys, els qual manifesten agressivitat i pertorben les activitats de classe, que no poden conservar bones amistats amb altres nens i que no poden establir-se en el grup dels seus companys, corren riscos greus (Hartup, 1992).

Quan un xiquet té relacions socials de qualitat, pot millorar-ne la Competència Social. D'aquesta manera, disposarà de més recursos per resoldre els conflictes que puguen donar-se tant amb professors com al seu grup d'iguals dins l'escola. I cal que el professor també incloga al seu repertori d'actuació el desenvolupament de la Competència social dels seus alumnes (Navarro, Gregori i Jiménez, 2013).

\section{Aportacions psicològiques a l'estudi de la Competència Social}

Els distints corrents psicològics han dut a terme diverses aportacions en el camp d'estudi de la Competència Social. Padés $(2003,2010)$ arreplega que les distintes disciplines científiques han emmarcat en les seues teories l'estudi de la Competència Social. Destaquem breument a continuació els principis i coneixements que cadascuna ha aportat a l'objecte d'estudi que ens incumbeix:

A. En la Teoria de l'Aprenentatge Social cal resaltar a Bandura (1987). L'autor estableix el comportament social com a resultat de la combinació dels factors ambientals i situacionals amb els processos cognitius i 
motivacionals de la persona. Els processos rellevants que afecten a la Competència Social són el reforçament directe, l'aprenentatge observacional, el modelat, l'autoeficàcia i l'autoregulació del comportament, entre d'altres. En conclusió, l'actuació social de la persona es veu determinada tant per variables intrínseques com extrínseques de la persona.

B. La Psicologia Social estableix que aspectes com ara la comunicació no verbal, la percepció social o els rols són processos que incideixen directament en la competència social i com es desenvolupa. Des d'aquest àmbit, se'n fa referència als processos interpersonals, en el sentit de què l'autoobertura cap a la resta i la responsivitat permeten establir intimitat en les relacions amb altres persones. Per això, la resposta que dóna la resta exerceix una influència sobre la pròpia interacció social establerta entre els individus, però també en la competència social (Laurenceau, Feldman i Pietromonaco, 1998).

C. Altre àmbit d'estudi de la Competència Social ha estat la Neurobiologia, en què s'ha intentat establir els tipus de sistemes i estructures neuronals que hi participen, així com els gens que influeixen en la cognició social i les estructures mentals que intervenen en la percepció dels estímuls socials, la seua relació amb l'emoció i la motivació (Adolphs, 2001; Tillfors, 2004).

D. Des de la Teràpia de Conducta destaquen els estudis d'Skinner (1963), qui va constatar que els aspectes cognitius de la persona contribueixen a explicar els comportaments socials. Des d'aquesta perspectiva, també s'hi ha aportat un marc metodològic útil pel que fa a tècniques d'anàlisi del comportament social.

\section{Aprenentatge i desenvolupament de la Competència Social}

La competència social permet a la persona la seua plena integració en la societat, i és una part fonamental de l'activitat humana (Martínez, Justicia i Cabezas, 2010). Ha de ser, a més, apresa, per la qual cosa no s'ha de deixar la seua formació a l'atzar. És la infància el període crític per a l'aprenentatge (Bellack i Morrison, 1982) i posterior desenvolupament de la competència social, malgrat que cal dir que aquesta última canvia progressivament amb l'edat degut a la maduració i l'aprenentatge. Tant els factors biològics com els culturals incideixen a la maduració de la competència social. La influència biològica és més forta als primers anys de la infància, moment en què la família juga un paper central com a eix de la socialització, mentre que en l'edat adulta són les experiències individuals les que millor determinen el grau de competència social de la persona.

Padés (2003) recull l'absència de dades definitives sobre el moment i la manera en què s'aprén a actuar de forma socialment habilidosa. Distints estudis 
apunten a la interacció entre els factors ambientals i genètics, que hi participen en aquest procés (Rotter, 1966; Meinchembaum, 1977; Mischel, 1981 i Bandura, 1986). Bellack i Morrison (1982) consideren que la Teoria de l'Aprenentatge Social és l'explicació més adequada per a l'aprenentatge primerenc de les conductes socials que fan a l'individu competent. Dins aquest model, el factor crític és el modelat (aprenentatge per observació o vicari), és a dir, l'observació directa dels xiquets als seus pares o iguals de les conductes que manifesten. Durant el període de l'adolescència, adquireixen major importància com a models el grup d'iguals, en què s'estableixen reforçaments forts.

Sánchez (2008) determina algunes de les característiques més destacables de l'aprenentatge de la competència social durant l'adolescència, on caldria ressaltar la importància que hi exerceix el grup d'iguals. Entre aquestes característiques, trobem la percepció de l'amistat com a un vincle estable malgrat la distància, la diferenciació entre el grup degut a conductes, actituds, formes de vestir, etc. $\mathrm{i}$ la tendència homogènia quant al sexe dels membres que formen una colla d'adolescents.

En l'adquisició de conductes socials, s'aprenen amb facilitat les que refereixen a l'estil d'interacció, tant verbal com no verbal. El manteniment d'aquestes conductes estarà condicionat per les experiències d'èxit o fracàs que s'experimenten quan es duen a terme (Argyle, 1969).

Altres autors, com ara Clemente (2011), recullen la importància de l'aplicació de programes d'intervenció primerenca prèvia a l'escolarització, la qual cosa es deu a què la implementació es caracteritza per proposar actuacions centrades en el xiquet que n'afavoreixen la socialització fora de l'entorn familiar. Així doncs, la importància d'aquests programes radiquen en la rellevància del desenvolupament de la competència social, emocional i intel-lectual de les persones durant els primers anys de vida. A més, Jiménez i López (2011), assenyalen que l'èxit assolit amb el grup d'iguals està molt relacionat amb la manifestació de comportaments vinculats a la competència social, la qual cosa ha de donar-se a més d'una manera constant. Del mateix mode, els joves que no mostren aquestes conductes mostren un fracàs social amb els seus iguals.

D'altra banda, el desenvolupament fa menció al grau de competència social que una persona adquireix i és capaç de manifestar mitjançant diversos comportaments que contribueixen a què responga de manera ajustada a les demandes socials que se li exigeixen des del propi entorn. Per a assolir un bon desenvolupament de la competència social, és necessària l'emergència de capacitats cognitives que s'aprenen en les successives interaccions socials a través de mecanismes com ara l'experiència directa, l'observació, la instrucció o el feedback interpersonal.

Per a avaluar la conducta social, cal destacar la importància del context social, donat que les conductes de les persones s'ajusten als criteris que hi deman- 
da l'entorn. Si tenim en compte la significació del context cultural, existeix un consens en la investigació d'aquest constructe que apunta a què distints contextos es relacionen amb distints resultats en la Competència Social en funció del impacte que exerceix. Així, el context actua sobre els factors de risc de dues formes distintes (Soriano i Soriano, 1994). D'una banda, protegeix front a components de risc, donat que proporciona un sistema de suport, normes i valors que contribueix a l'afirmació positiva de l'individu. D'altra, si no es donés aquesta protecció, l'individu quedaria debilitat per elements socials i econòmics hostils, inclús per processos d'exclusió social, que poden conduir-lo a establir-se en cultures marginals (Roberts, Garritz i Kearney, 1990).

Pel que fa a l'estudi de la competència social en funció del nivell socioeconòmic, destaquem el treball de Trianes, Cardelle, Blanca i Muñoz (2003). Arran l'avaluació de les competències de tres grups d'adolescents (de nivell socioeconòmic alt, mitjà i baix), hi van observar diferències quant a l'assertivitat i agressivitat. El grup que pertanyia a una classe social acomodada mostrava una major assertivitat $\mathrm{i}$ un baix grau de passivitat i agressivitat front les relacions amb els adults. Els adolescents que corresponien a un nivell mitjà es diferenciaven del grup anterior per presentar baixa agressivitat $i$ assertivitat, mentre que una alta passivitat. L'últim grup, manifestava una agressivitat alta, passivitat a un grau mig i, incoherentment, una assertivitat elevada.

Altres estudis, com ara els de López, Garrido i Ross (2001), Rodríguez i Grossi (1999) i López, Garrido, Rodríguez i Paíno (2002) assenyalen que la competència social és fonamental per assolir una adaptació social adequada, així com personal i escolar. Arce, Fariña, Mohamed i Seijo (2010), per la seua banda, revelen que un grau baix de competència social es relaciona amb l'abandó i fracàs escolar, a més de la manifestació de conductes delictives i comportaments antisocials. Posteriorment, Arce, Fariña i Vázquez evidenciarien aquest fet al seu treball (2011).

En qualsevol cas, pot afirmar-se que la competència social es desenvolupa al llarg de tota la vida. Cada context social conté unes normes i valors que regeixen les relacions socials que s'hi donen. L'avaluació de les seues característiques és una línia d'investigació interessant en aquest àmbit, ja que pot contribuir a interpretar més precisament les diferències que se'n troben entre els adolescents que pertanyen a diferents contextos socioculturals.

\section{Influència de les variables sexe, edat i nota mitjana en la Competència Social}

La variable sexe ha estat molt present en la producció científica de la Psicologia, especialment en la Psicologia actual (Mestre, Martí-Vilar i Samper,

1998d). De fet, els investigadors destaquen que generalment la tendència a 
empatitzar figura entre les característiques que les persones atribueixen més frequientment a les dones que als homes (Mestre, Pérez, Samper i Martí-Vilar, 1998a , 1998b), i així ocorre també amb la Competència Social. Aquesta percepció té relació amb els estereotips socials que atribueixen a la dona una major sensibilitat emocional, tendència a l'atenció i suport als més dèbils i a la detecció de sentiments i senyals no verbals, així com més preocupació pels aspectes socials de la interacció i els sentiments cap a la resta. Les diferències en la normativa social sobre els rols sexuals fa més adequat per a les dones manifestar tant sentiments d'enuig i ansietat com de tendresa i compassió (Batson i al., 1995: 1043).

Els estudis realitzats amb població espanyola conclouen que les dones presenten major disposició empàtica que els hómens, tant en l'adolescència com en la joventut, i que la capacitat empàtica s'incrementava amb l'edat a causa del desenvolupament cognitiu i la presa de perspectiva social (Fuentes, 1989; Mestre, Pérez, Martí-Vilar, Samper i Soler, 1998a; Mestre, Pérez, Samper i MartíVilar, 1998b; 1998c; Martí-Vilar i Palma, 2011).

Existeixen investigacions que contemplen les diferències en competència social en funció del gènere, encara que en són escassos. Des d'un corrent evolutiu, s'ha constatat que en xics i xiques de la mateixa edat, són les xiques qui mostren un major desenvolupament cognitiu-social (Hawley, 2003), la qual cosa radica en un major grau de competència social.

Altres estudis coincideixen en què els adolescents busquen abastar una identitat social acceptable, cosa que condueix en moltes ocasions als xics a mostrar conductes agressives i evitar-hi aquelles que puguen considerar-se «femenines» (Giles i Heyman, 2005; Gini i Pozzoli, 2006; Stoudt, 2006). Aquestes conductes «femenines» es corresponen amb una major competència social.

Diferents investigacions han assenyalat que al llarg de l'adolescència la capacitat cognitiva aplega a ser més sofisticada, degut en part a un augment de la intel-ligència, la capacitat de posar-se en el lloc de l'altre i l'habilitat de pensar en abstracte (Martí-Vilar, 2001; Martí-Vilar i Palma, 2009).

Els canvis cognitius relacionats amb l'edat dels estudiants (Martí-Vilar, 2001), així com la seua formació, possibiliten una major maduresa moral, concretament més qualitat i complexitat per pensar sobre conflictes morals (Mestre, Pérez, Samper i Martí-Vilar, 1995; Fuentes, Mestre, Pérez i Martí-Vilar, 1996). Des d'aquesta perspectiva cognitivo-evolutiva, un tipus de raonament més complex i interioritzat es relaciona més freqüentment amb conducta prosocial i amb una millor qualitat d'aquesta (Eisenberg i al. 1991).

Sens dubte, el desenvolupament de la cognició moral i la competència social estan molt relacionats si s'estudien des de la perspectiva de Piaget, ja que va ser aquest autor qui va defendre l'existència d'una transició entre les distintes etapes del juí moral, i va considerar que hi ha un procés de maduració 
des d'una moral heterònoma fins l'autonomia moral, una convergència entre desenvolupament moral i cognitiu, una activitat de la persona en la construcció del coneixement del món, el seu significat i l'assimilació d'experiències socials en pautes, i una diversitat de percepció i interpretació de situacions socials (Buxarrais, 2000).

En la infància, les interaccions a través del joc són molt importants, ja que a partir d'aquest, és possible que tracten de buscar allò que és just, inclús en qüestions problemàtiques, la qual cosa afavoriria el desenvolupament del pensament moral autònom. Per això, l'habilitat per a actuar des del sentit de la reciprocitat i respecte s'associa al pas cap a la presa de la perspectiva social, des de l'egocentrisme. En aquesta interacció i maduració, els xiquets passen de l'egocentrisme ja esmentat cap a la descentració, tenen major contacte amb altres punts de vista, n'estableixen els propis codis sobre què és just $\mathrm{i}$ decideixen quines són les regles que seguiran, així com que se n'adonen de què són capaços de plantejar els seus codis morals (Pérez, Mestre, Martí-Vilar i Samper, 1996; Martí-Vilar, 2008; Martí-Vilar i Palma, 2010).

En relació a la influència que l'edat i el procés maduratiu exerceixen sobre el desenvolupament de la competència social, destaquen els estudis d'Argyle (1969), els quals apunten a què la maduració i les experiències d'aprenentatge suposen un desenvolupament de la competència social. Altres autors, com ara Schaffer (1984) i Moreno i Cubero (1990), concreten encara més en referir-se a la infància com el període clau per a l'aprenentatge de les habilitats socials. Si es té en compte la literatura referent a la competència social en relació a la variable edat, s'esperarà que a mesura que avança l'edat, la competència social siga major.

L'escola és un context en què els adolescents estan immersos i hi apareixen contínuament nombroses demandes referides a la competència social. Diversos estudis han contemplat la relació existent entre aquest constructe i el rendiment acadèmic, i mostren la importància de les habilitats socials en l'escola (Elias, Chan i Caputi, 2000; Gil-Olarte, Palomera i Brackett, 2006; Lopes i Salovey, 2004; Pool, 1997). Altres investigacions de caràcter longitudinal, com ara la de Chen i al., 1997 i Bush i Ladd, 2001, han arribat a la conclusió de què el rendiment acadèmic prediu la competència social i l'acceptació dels iguals.

\section{Aproximacions actuals a l'estudi de la Prosocialitat}

En analitzar la literatura recent al respecte de l'estudi del comportament prosocial, trobem com a autor destacat a l'italià Caprara, que junt amb un equip de collaboradors experts, mesuren el constructe, sovint en relació a altres, a través d'estudis longitudinals. Els dos treballs més recents estudien la relació entre la prosocialitat i l'autoestima en persones des dels 21 anys fins els 25 , i 
un d'ells se centra en la relació d'aquests dos constructes de cara a la qualitat de l'amistat. En ambdós casos, es donen resultats favorables a confirmar que el comportament prosocial és un predictor positiu de l'autoestima percebuda i s'hi observa un increment paral·lel (Zuffianò, i al., 2014).

Altre estudi longitudinal centra la seua investigació als canvis de personalitat en un grup d'adolescents des dels 13 fins els 21 anys, mitjançant l'administració del qüestionari dels Cinc Grans factors de personalitat ${ }^{1}$ (Goldberg, 1993). El grup amb un major increment progressiu de comportament psicosocial experimenta així canvis significativament positius en les característiques d'Amabilitat i Obertura a l'experiència, mentre que el grup amb menor increment mostra una millora en el tret de Responsabilitat (Luengo, i al. 2014).

\section{Metodologia}

\section{Objectius}

L'objectiu principal es concreta en els següents de caràcter específic:

1. Avaluar la preferència de la competència social en estudiants de secundària.

2. Establir les diferències en la Competència Social en funció del sexe, l'edat i la nota mitjana.

\section{Descripció de la mostra}

La mostra de 193 adolescents és incidental i s'ha aplicat a l'atzar a estudiants d'Educació Secundària Obligatòria (ESO) d'ensenyaments públic i concertat.

En relació a la variable sexe, 96 alumnes $(49,7 \%)$ són dones i 97 (50,3\%) són varons. Per tant, podem destacar que la mostra està equilibrada. Pel que fa a l'edat, la mitjana d'aquesta mostra està en els 14 anys (DT=1,26 anys) i la moda és també de 14 anys.

L'edat oscil·la entre els 12 i els 16 anys, distribuïts del següent mode en relació a aquesta variable: 12 anys $(16,6 \%), 13$ anys $(21,8 \%), 14$ anys $(26,4 \%)$, 15 anys $(23,3 \%)$ i 16 anys $(11,9 \%)$.

La tercera variable que s'analitzarà és la nota mitjana que aquests estudiants van obtindre el curs anterior. Les notes acadèmiques de la mostra són les següents: Suficient $(11,4 \%)$, Bé $(34,7 \%)$, Notable $(45,6 \%)$ i Excel-lent $(8,3 \%)$.

1. A recordar: Obertura a l'experiència, Responsabilitat, Extraversió, Amabilitat i Inestabilitat emocional. 


\section{Instrument}

L'instrument que s'ha emprat per a l'avaluació de la competència social és, com ja s'ha esmentat anteriorment, The Matson Evaluation of Social Skills in Youngsters (MESSY), de Matson i al. (1983). Destaca pel seu disseny dirigit a l'avaluació del grau d'adequació de la conducta social, l'ajustament general de la persona, $i$ del qual a més existeixen dues variants: una per a professorat $i$ altra per a alumnes de 4 a 18 anys (aquesta última és la que hem utilitzat). Permet mesurar problemes del comportament social, així com les habilitats i competències adequades. L'aplicació de la ferramenta s'ha dut a terme amb la traducció i adaptació realitzada per Trianes i col-laboradors (2002), i la revisió de la mà de Méndez, Hidalgo e Inglés (2002).

El qüestionari consta de 62 ítems que informen sobre quatre dimensions del constructe: Habilitats socials apropiades, Assertivitat inapropiada, Sobreconfiança-Orgull i Cels-Soledat. La forma de resposta està constituïda per una escala tipus Likert amb quatre opcions de repsosta: Mai (1), De vegades (2), Sovint (3) i Sempre (4); cal tenir en compte que a major puntuació de resposta, major presència de la dimensió del constructe.

Segons Caurcel (2009), les propietats psicomètriques de l'instrument han estat investigades quantiosament, sobre tot en mostres angloparlants, a partir de les quals s'ha obtingut un resultat satisfactori de l'alfa de Cronbach $=.80$ (Helsen i Matson, 1984; Kazdin, Matson i Elveldt-Dawson, 1984; Matson, Macklin i Helsel, 1985; Matson i Ollendick, 1988; Spence i Liddle, 1990). En mostres espanyoles (Mendez, Hidalgo e Inglés, 2002) en la seua aplicació a 634 adolescents d'entre 12 i 17 anys, es va trobar també una elevada consistència interna $\mathrm{amb}$ una alfa de Cronbach $=.88$.

\section{Procediment}

Per al correcte desenvolupament d'aquest estudi, es va executar una sistematització exhaustiva dels passos. Es va sol-licitar la participació de dos centres d'ensenyament secundari, i es va exposar de forma clara els objectius de la investigació, el tipus de col-laboració que s'esperava del centre i els beneficis.

La recollida de dades a través de l'instrument citat reiteradament es va realitzar durant les hores de tutoria al llarg de diversos dies de març a maig de 2009. Les dades obtingudes dels diferents qüestionaris s'han introduït al programa estadístic SPSS 21.0 per a Windows, en què es van calcular, per a l'alumnat que componen la mostra, les puntuacions obtingudes en cadascuna de les subescales de l'instrument.

Aquesta investigació constitueix un estudi transversal i les variables independents que s'hi han considerat són el sexe, l'edat i la nota mitjana del curs im- 
mediatament anterior. Per la seua banda, la variable dependent que mesurarem serà la Competència Social operacionalitzada a través del MESSY.

\section{Resultats}

Aquest apartat permet analitzar el grau d'habilitat social que mostra l'alumnat de secundària, participant d'aquesta investigació, i la influència que hi exerceixen les variables independents ja esmentades.

\section{Resultats generals}

A la taula 1 es recullen les puntuacions mínimes, màximes, mitjanes i desviacions típiques que el grup d'estudiants de la mostra ha obtingut en cadascuna de les subescales del MESSY. Aquest instrument (Matson i al., 1983) permet abordar el constructe de Competència Social a través de quatre subescales: $\mathrm{Ha}$ bilitats Socials Apropiades, Assertivitat Inapropiada, Sobreconfiança-Orgull i Cels-Soledat. En consequiència, el MESSY permet mesurar problemes del comportament social i també les habilitats i competències adequades.

TAULA 1

Puntuacions generals de la mostra en Competència Social

\begin{tabular}{|l|c|c|r|r|}
\hline & Mínim & Màxim & Mitjana & \multicolumn{1}{c|}{ DT } \\
\hline Habilitats Socials Apropiades, & 55 & 97 & 82,82 & 8,21 \\
Assertivitat Inapropiada & 29 & 87 & 46,59 & 10,49 \\
Sobreconfiança- Orgull & 5 & 20 & 8,68 & 3,15 \\
Cels- Soledat & 8 & 20 & 12,46 & 1,84 \\
\hline
\end{tabular}

En considerar les puntuacions mitjanes de la mostra, obtingudes en cadascuna de les subescales, comprovem que els adolescents han tret majors puntuacions, primerament, en l'escala d'Habilitats Socials Apropiades, seguit d'Assertivitat Inapropiada, en tercer lloc de la subescala Cels-Soledat i per últim en Sobreconfiança-Orgull.

\section{Efecte de les variables sociodemogràfiques en Competència Social}

\section{COMPETÈNCIA SOCIAL I LA VARIABLE «SEXE»}

En aquest apartat, pretenem veure la influència que aquesta variable exerceix sobre la Competència Social, per a la qual cosa s'ha realitzat una anàlisi ANOVA d'un factor (sexe) per a les subescales del qüestionari. 
La mostra d'aquesta investigació té un nombre equilibrat pel que fa a la quantitat de dones i hómens, és a dir, 96 dones (49.7\%) i 97 homes (50.3\%).

Podem observar a la taula $2 \mathrm{com}$ la variable esmentada produeix efectes significatius en tres de les subescales.

TAULA 2

Interacció del sexe en les subescales del MESSY

\begin{tabular}{|c|c|c|c|c|}
\hline & $\begin{array}{c}\text { HABILITATS SOCIALS } \\
\text { APROPIADES }\end{array}$ & $\begin{array}{l}\text { ASSERTIVITAT } \\
\text { INAPROPIADA }\end{array}$ & $\begin{array}{c}\text { SOBRECONFIANÇA } \\
\text { ORGULL }\end{array}$ & $\begin{array}{c}\text { CELS } \\
\text { SOLEDAT }\end{array}$ \\
\hline Dona & 86,14 & 44,16 & 8,06 & 12,25 \\
\hline Home & 79,53 & 49 & 9,3 & 12,68 \\
\hline$F$ & 37,08 & 10,75 & 7,79 & 2,63 \\
\hline$p$ & ,000 & 001 & ,006 & ,106 \\
\hline
\end{tabular}

En la taula anterior s'aprecien diferències estadísticament significatives en les puntuacions de les distintes escales. Les dones obtenen valors i diferències estadísticament significatives superiors als hómens en Habilitats Socials Apropiades, i puntuacions i diferències significatives menors front a ells en Assertivitat Inapropiada i Sobreconfiança-Orgull.

\section{COMPETÈNCIA SOCIAL I LA VARIABLE «EDAT»}

En aquesta secció de l'anàlisi, s'ha intentat esbrinar la influència de la variable edat en les quatre subescales sobre els adolescents que en componen la mostra. Per a açò, s'ha dut a terme una classificació dels cinc grups d'edat que la constitueixen: 12 anys (16.6\%), 13 anys (21.8\%), 15 anys (23.3\%) i 16 anys (11.9\%). S'ha elaborat d'aquesta manera per tal de saber si un únic any cronològic originava diferències estadísticament significatives en les subescales de la Competència Social. L'anàlisi realitzada és l'ANOVA d'un factor entresubjectes amb cada subescala (veja's taula 3 ).

L'edat dels subjectes té un efecte estadísticament significatiu en la subescala Sobreconfiança-Orgull $(\mathrm{p}=0.1)$. tal com podem observar a la taula 3, la Sobreconfiança-Orgull augmenta linealment en relació a l'edat de la mostra, és a dir, a més edat, els valors mostrats en aquesta subescala són majors, amb l'excepció del grup d'edat de 16 anys. 
TAULA 3

Interacció de la variable edat en la Competència Social

\begin{tabular}{|r|c|c|c|c|}
\hline & $\begin{array}{c}\text { HABILITATS SOCIALS } \\
\text { APROPIADES }\end{array}$ & $\begin{array}{c}\text { ASSERTIVITAT } \\
\text { INAPROPIADA }\end{array}$ & $\begin{array}{c}\text { SOBRECONFIANÇA } \\
\text { ORGULL }\end{array}$ & $\begin{array}{c}\text { CELS } \\
\text { SOLEDAT }\end{array}$ \\
\hline 12 anys & 83,56 & 46,06 & 8,56 & 12,03 \\
\hline 13 anys & 83,57 & 44,57 & 7,64 & 12,33 \\
\hline 14 anys & 83 & 48,33 & 9,07 & 12,23 \\
\hline 15 anys & 81,4 & 48,62 & 9,75 & 13,15 \\
\hline 16 anys & 82,82 & 43,21 & 7,82 & 12,47 \\
\hline \multirow{2}{*}{$F$} &, 49 & 1,80 & 3,21 & 2,32 \\
\cline { 2 - 5 } &, 74 &, 130 & $\mathbf{, 0 1}$ &, 058 \\
\hline
\end{tabular}

Els resultats continguts en la taula 4 mostren les proves post-hoc aplicades a la subescala en qüestió, on s'han constatat diferències significatives. Així doncs, s'aprecien les diferències existents entre els subjectes de 13 anys i els de 15 anys, i aquests últims són qui puntuen més alt en la subescala abans esmentada.

TAULA 4

Comparacions entre grups d'edat en Sobreconfiança-Orgull

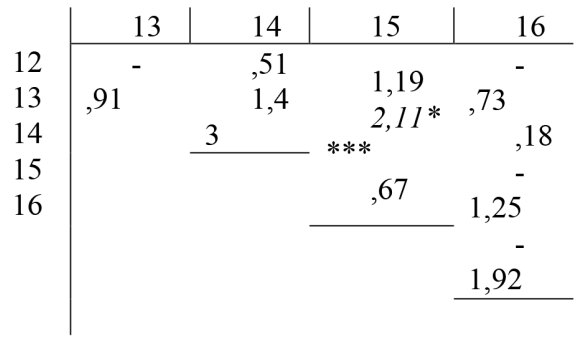

Valor: diferència de mitjanes; $* * * *$ Turkey HDS, Bonferroni i Games-Howell.

\section{COMPETÈNCIA SOCIAL I LA VARIABLE «NOTA MITJANA»}

L'anàlisi d'aquest últim apartat té com a finalitat estudiar si la nota mitjana acadèmica obtinguda per l'alumnat al curs anterior té influència sobre la competència social. Amb aquest objectiu, s'ha realitzat l'ANOVA entre-subjectes d'un factor. La mostra de la investigació està compensada amb un 46.1\% (89 alumnes) per a les notes baixes i un 53.9\% (104 alumnes) per a les notes altes. 
TAULA 5

Interacció de la nota mitjana sobre la Competència Social

\begin{tabular}{|r|c|c|c|c|}
\hline & $\begin{array}{c}\text { HABILITATS SOCIALS } \\
\text { APROPIADES }\end{array}$ & $\begin{array}{c}\text { ASSERTIVITAT } \\
\text { INAPROPIADA }\end{array}$ & $\begin{array}{c}\text { SOBRECONFIANÇA } \\
\text { ORGULL }\end{array}$ & $\begin{array}{c}\text { CELS } \\
\text { SOLEDAT }\end{array}$ \\
\hline Suficient & 81,95 & 47,4 & 8,4 & 13,09 \\
\hline Bé & 81,47 & 48,4 & 8,56 & 12,79 \\
\hline Notable & 83,19 & 46,01 & 8,85 & 12,11 \\
\hline Excel·lent & 87,62 & 41,12 & 8,68 & 12,18 \\
\hline \multirow{2}{*}{$F$} & 2,62 & 2,29 &, 16 & 2,79 \\
\cline { 2 - 5 }$p$ &, 05 &, 08 &, 91 &, $\mathbf{0 4}$ \\
\cline { 2 - 5 } & & & &
\end{tabular}

Els resultats anteriors mostren com la nota mitjana és una variable que influeix en la subescala de Cels-Soledat, on les diferències de puntuació obtingudes per l'alumnat són estadísticament significatives. A la taula 4 pot veure's com l'alumnat, que presenta notes mitjanes més baixes, puntua més alt en CelsSoledat.

La taula 5, per la seua banda, mostra diferències estadísticament significatives en les puntuacions assolides pels alumnes en la subescala de Soledat. Apareix marcada una tendència lineal descendent, en què qui obté puntuacions mitjanes més baixes mostren nivells de soledat més elevats. Contràriament, els qui treuen notes més altes, manifesten una soledat menor.

La taula 6 apila els resultats de les proves post-hoc aplicades a les distintes escales que mesuren el constructe que ens concerneix. Aquests valors mostren com la nota mitjana és una variable que té influència sobre la Competència Social, en què les diferències de puntuació obtinguda per l'alumnat són estadísticament significatives.

Es constaten unes diferències estadísticament significatives en les puntuacions obtingudes per l'alumnat en l'escala d'Habilitats Socials Apropiades, en què els qui obtenen una mitjana d'Excel·lent puntuen significativament més alt que els qui presenten una nota mitjana de Suficient o Bé. D'altra banda, són destacables els resultats aconseguits en la subescala d'Assertivitat Inapropiada, on els qui obtenen puntuacions estadísticament més altes són els qui obtenen una nota de Bé, en relació a qui tenen Excel·lent. 
TAULA 6

Proves post-hoc de la nota mitjana en Competència Social

\begin{tabular}{|c|c|c|c|}
\hline \multicolumn{4}{|c|}{ HABILITATS SOCIALS APROPIADES } \\
\hline & Bé & Notable & Excel-lent \\
\hline Suficient &,- 47 & 1,23 & $5,67^{* *}$ \\
\hline Bé & & 1,71 & $6,14^{* * * * *}$ \\
\hline Notable & & & 4,43 \\
\hline \multicolumn{4}{|c|}{ ASSERTIVITAT INAPROPIADA } \\
\hline & Bé & Notable & Excel-lent \\
\hline Suficient &,- 99 & $-1,39$ & $-6,28$ \\
\hline Bé & & $-2,39$ & $-7,27^{* *}$ \\
\hline Notable & & & $-4,88$ \\
\hline \multicolumn{4}{|c|}{ SOBRECONFIANÇA-ORGULL } \\
\hline & Bien & Notable & Excel·lent \\
\hline Suficient &,- 15 &,- 12 &, 27 \\
\hline Bé & &, 44 &, 12 \\
\hline Notable & & &,- 16 \\
\hline \multicolumn{4}{|c|}{ CELS-SOLEDAT } \\
\hline & Bé & Notable & Excel-lent \\
\hline Suficient &,- 29 &,- 97 &,- 90 \\
\hline Bé & &,- 67 &,- 60 \\
\hline Notable & & & 073 \\
\hline
\end{tabular}

Valor: diferència mitjanes; ${ }^{* *}$ Games-Howell; Bonferroni.

***** Turkey HSD, Games-Howell i Bonferroni.

La diferència de mitjanes és significativa al nivell .05 .

\section{Discussió}

Dins l'àmbit acadèmic, van apareixent molts estudis que apunten a què la Competència Social estableix beneficis per a l'èxit acadèmic i l'accés al currículum, a més de la incipient necessitat de fomentar comportaments cívics en el context escolar. Un d'aquests estudis seria el treball de Caprara i al. (2015) en què s'implementa un programa d'intervenció específicament dedicat a millorar 
el comportament prosocial, anomenat Promoure Habilitats Prosocials i Emocionals per a Contrarestar Problemes Externs -CEPIDEA segons les sigles en italià-. Arran la seua aplicació sobre un grup d'intervenció, s'hi dóna un increment en el comportament prosocial, la creença d'autoeficàcia interpersonal i l'amabilitat, així com en la resposta d'agressió física, per damunt de la tendència normativa de aquestes variables (Caprara, Luengo, Zuffianò, Gerbino i Pastorelli, 2015). Si ens centrem en el nostre estudi, podríem extreure les següents conclusions:

1. Des d'aquest estudi, i mitjançant l'anàlisi de les puntuacions obtingudes pels adolescents de la mostra que el constitueix, podem constatar que s'ha obtingut una puntuació major en Habilitats Socials Apropiades i una menor en Assertivitat Inapropiada. Aquests primers resultats indiquen que el grup d'adolescents mostra majoritàriament una predisposició a resoldre de mode satisfactori les interaccions personals.

En la investigació que s'ha desenvolupat, 166 dels 193 alumnes que participaven en l'estudi han assolit puntuacions mitjanes $i$ altes en competència social, la qual cosa revela que els que els adolescents abasten nivells elevats de Competència Social. Aquests resultats suporten les afirmacions de Rubin i Rose-Krasnor (1992), en constatar que les habilitats socials en l'adolescència són el manteniment de les relacions interpersonals i l'habilitat per resoldre problemes socials. Per aquest motiu, la Competència Social està significativament relacionada amb el desenvolupament social dels adolescents.

2. En analitzar la variable sexe, s'observen diferències estadísticament significatives en les subescales d'Habilitats Socials Apropiades, Assertivitat Inapropiada i Sobreconfiança-Orgull. Açò suposa que els homes mostraran una tendència major cap a les conductes antisocials i l'orgull, i un menor grau d'habilitat social en comparació a les dones.

Aquests resultats estan en consonància amb els estudis de Hawley (2003), qui va constatar que en xics i xiques de la mateixa edat, són elles qui mostren un major desenvolupament cognitiu-social, i són al mateix temps més competents a nivell social. També, les investigació de Giles i al. (2005), Gini i al. (2006) i Stoudt (2006) afirmen que els xics adolescents cerquen abastar una identitat social acceptable, la qual cosa els sol conduir en reiterades ocasions a mostrar conductes agressives i evitar-ne les considerades «femenines». Amb açò, podria concluir-se que en les diferències de gènere quant a la Competència Social hi estan implicats factors tant emocionals com cognitius.

3. L'anàlisi de la relació entre la Competència Social i la variable edat ha demostrat diferències estadísticament significatives, en tant que s'ha manifestat una puntuació significativament major en la subescala Sobreconfiança-Orgull en el grup de 15 anys que en el de 13. 
4. Pel que fa a la relació amb la variable nota mitjana, s'han trobat diferències estadísticament significatives en l'alumnat que tenen una mitjana d'Excellent. En primer lloc, mostren puntuacions majors en l'escala d'Habilitats Socials Apropiades respecte als grups amb mitjana de Suficient i Bé. També cal destacar que obtenen puntuacions menors que el grup amb una nota mitjana de Bé en la subescala de Assertivitat Inapropiada. Aquestes conclusions es corresponen amb els estudis d'Elias i al. (2000), Gil-Olarte i al. (2006), Lopes i Salovey (2004) i Pool (1997).

Tal i com s'estableix al llarg d'aquest estudi, les tres variables independents ja esmentades exerceixen una influència estadísticament significativa en la Competència Social, de la qual cosa deriva la rellevància de considerar els resultats del present estudi. Per això, també es conclou que el desenvolupament de la Competència Social pot ser un dels mitjans que contribueixen no només a solucionar els conflictes de convivència, sinó també potenciar unes vertaderes relacions humanes.

L'anàlisi de la Competència Social ajuda a activar vies d'aprenentatge ètic per què l' alumnat puga elaborar-ne i construir-ne la maduresa i autonomia moral (Martí-Vilar, 2008), i tal i com afirmen Pérez, Mestre i al. (1999), el desenvolupament d'un jo ferm i segur pot ser un factor protector front a molts problemes.

\section{Referències}

Argyle, M. (1967). The psychology of interpersonal behavior. London: Penguin Argyle, M. (1969). Social Interaction. Londres: Methuen.

Argyle, M. i Kendon, A. (1967). The experimental analysis of social performance. Advances in Experimental Social Psychology, 3, pp. 55-98.

Bandura, A. (1987). Teoría del aprendizaje social. Madrid: Espasa-Calpe.

Batson, C. D.; Klein, T. R. i al. (1995). Immorality from empathy-induced altruism: When compassion and justice conflict, Journal of Personality and Social Psychology, 68, pp. 1042-1054.

Bellack, A. S. i Morrison, R. L. (1982). Interpersonal dysfunction. En A. S. Bellack, M. Hersen i A. E. Kazdin (Comps.), International handbook of behavior modification and therapy. Nueva York: Plenum Press.

Buhs, E. i Ladd, G. W. (2001). Peer rejection as antecedent of young children's school adjustment: An examination of mediating processes. Developmental Psychology, 37, pp. 550-560.

Buxarrais, M. R. (2000). Tendencias y modelos de educación moral. Diálogo Filosófico, 47, pp. 199-200.

Caballo, V. E. (1983). Asertividad: definiciones y dimensiones. Estudios de Psicología, 13, pp. 52-62. 
Caprara, G. V.; Luengo Kanacri, B. P.; Zuffianò, A.; Gerbino, M. i Pastorelli, C. (2015). Why and How to Promote Adolescents' Prosocial Behaviors: Direct, Mediated and Moderated Effects of the CEPIDEA School-Based Program. Journal of Youth and Adolescence, 44(12), pp. 2211-2299.

Caurcel, J. (2009). Estudio evolutivo del maltrato entre iguales desde la percepción y el razonamiento sociomoral de los implicados. Tesis Doctoral. Granada: Universidad de Granada.

Chen, X.; Chang, L. i He, Y. (1997). Relations between academic achievement and social adjustment: Evidence from Chinese children. Development Psychology, 33(3), pp. 518-525.

Eisenberg, N.; Miller, P. A.; Shell, R.; Mcnalley, S. i Shea, C. (1991). Prosocial development in adolescence: A longitudinal study, Developmental Psychology, 27, pp. 849-857.

Elias, M. J.; Chan, A. Y. C i Caputi, P. (2000). A critical evaluation of the emotional intelligence construct. Personality and Individual Differences, 28(3), pp. 539-561.

Fuentes, E.; Mestre, M. V.; Pérez, E. i Martí-Vilar, M. (1996). Efecte del tipus d'estudi (Batxillerat/Formació Professional) en el desenvolupament del judici moral d'una població d'adolescents. Anuari de Psicologia de la Societat Valenciana de Psicologia, 3(1), pp. 57-76.

Gilar, R.; Miñao, P. i Castejón, J. L. (2008). Inteligencia Emocional y Empatía: su influencia en la Competencia Social en Educación Secundaria Obligatoria. SUMMA Psicológica, 5(1), pp. 2132.

Giles, J. W. i Heyman, G. D. (2005). Young children's beliefs about the relationship between gender and aggressive behaviour. Child Development, 76(1), pp. 107-121.

Gil-Olarte, P.; Palomera, R. i Brackett, M. A. (2006). Relating emotional intelligence to social competence and academia achievement in high school students. Psicothema, 18 (supl.), pp. 118-123.

Gini, G. i Pozzoli, T. (2006). The role of masculinity in children's bullying. Sex Roles, 54, pp. 585-588.

Gismero, E. (2000). Escala de habilidades sociales. Madrid: Tea Ediciones.

Hartup, W. W. (1992): Having Friends, Making Friends, and Keeping Friends: Relationships as Educational Contexts. Eric digest.

Hawley, P. H. (2003). Strategies of control, aggression and morality in preschoolers: An evolutionary perspective. Journal of Experimental Child Psychology, 85(3), pp. 213-235.

Helsel, W. J. i Matson, J. L. (1984). The assessment of depression of children: The internal structure of the Children's Depression Inventory (CDI). Behavior Research and Therapy, 22, pp. 289-298. 
Kazdin, A. E.; Matson, J. L. i Esveldt-Dawson, K. (1984). The relationship of role-play assessment of children's social skills to multiple measures of social competence. Behaviour Research and Therapy, 22, pp. 129-140.

Kelly, J. A. i Lamparski, D. M. (1985). Outpatient tratament of schizophrenics: Social skills and problem-solving training. En M. Hersen i A. S. Bellack (Comps.), Handbook of clinical behavior therapy with adults. Nueva York: Plenum Press.

Lopes, P. N. i Salovey, P. (2001). Emotional intelligence and social-emotional learning: assessing emotional intelligence and developing skills and flexibility. CEIC Review, 22, pp. 12-13.

Luengo Kanacri, B. P.; Pastorelli, C.; Eisenberg, N.; Zuffianò, A.; Castellani, V. i Caprara, G. V. (2014). Trajectories of prosocial behavior from adolescence to early adulthood: Associations with personality change. Journal of Adolescence, 37(5), pp. 701-713. doi: 10.1016/j.adolescence.2014.03.013.

Martí-Vilar, M. (2001). Influjo de la educación en el desarrollo moral, los valores y las creencias de los adolescentes. Tesis Doctoral. Valencia: Universitat de València.

Martí-Vilar, M. (2008). Las necesidades humanas desde la psicología moral. Papeles de relaciones ecosociales y cambio global, 102, pp. 89-101.

Martí-Vilar, M. i Palma, J. (2009). Influència del sexe i l'edat en el Raonament Moral Prosocial dels estudiants de secundaria. Anuari de Psicologia de la Societat Valenciana de Psicologia, 2, pp. 65-85.

Martí-Vilar, M. i Palma, J. (2010). Progreso en los modelos teóricos de la psicología sociomoral. En M. Martí Vilar, Razonamiento Moral y Prosocialidad. Fundamentos básicos (pp. 75-98). Madrid: CCS.

Martí-Vilar, M. i Palma, J. (2011). Diferencies de sexe i edat en la disposició empàtica dels estudiants de secundària. Anuari de Psicologia de la Societat Valenciana de Psicologia, 13(1-2), pp. 255-270.

Matson, J. L.; Rotatori, A. F. i Helsel, W. J. (1983). The Matson Evaluation of Social Skills with Youngsters (MESSY). Behavior Research Therapy 21(49), pp. 335-340.

Matson, J. L. i Ollendick, T. H. (1998). Enhancing children's social skills. New York: Pergamon Press.

Matson, J. L., Macklin, G. F. i Helsel, W. J. (1985). Psychometric properties of the Matson Evaluation in Social Skills with Youngsters (MESSY) with emotional problems and self concept in deaf children. Journal of Behavior Therapy an Experimental Psychiatry, 16, pp. 117-123.

Méndez, F. X., Hidalgo, M. D i Inglés, C. J. (2002). The Matson Evaluation of Social Skills with Youngsters: Psychometric properties of the Spanish translation in the adolescent population. European Journal of Psychological Assessment, 18(1), pp. 30-42. 
Mestre, M. V., Martí-Vilar, M. i Samper, P. (1996). Productividad científica en psicología y la variable género. Un estudio a través de la Revista de Psicología General y Aplicada. Revista de Historia de la Psicología, 17(1-2), pp. 121-133.

Mestre, M. V.; Pérez, E.; Samper, P. i Martí-Vilar, M. (1995). Función del Nivel Educativo y del Sexo en el Desarrollo Moral de los adolescentes. Revista de Psicología de la Educación, 18, pp. 59-71.

Mestre, M. V.; Pérez Delgado, E.; Martí-Vilar, M.; Samper, P. i Soler, J. V. (1998a). Diferencias Psicológicas en razón del género. Una visión multidimensional de la empatía en adolescentes. Teología Espiritual, XLI(122), pp. 437-452.

Mestre, M. V.; Pérez-Delgado, E.; Samper, P. i Martí-Vilar, M. (1998b). Diferencias de género en la empatía y su relación con el Pensamiento Moral y el Altruismo. Revista de Psicología General y Aplicada, 3(1), pp. 1-21.

Mestre, V.; Pérez, E.; Samper, P. i Martí-Vilar, M. (1998c). Conocimiento y afecto en el desarrollo moral de las personas. Efectos diferenciadores del sexo en cuanto a la empatía y el pensamiento moral. Teología Espiritual, $X L$, pp. 157-187.

Mestre, V.; Samper, P. i Martí-Vilar, M. (1998). La psicología actual desde la perspectiva del género. Un análisis de la literatura publicada a través del Psychological abstracts. Iberpsicología: Revista Electrónica de la Federación Española de Asociaciones de Psicología, 3(1).

Moreno, M. C. i Cubero, R. (1990). Relaciones sociales. Familia, escuela y compañeros. Años preescolares. En J. Palacios, A. Marchesi i C. Coll (Comps.), Desarrollo psicológico y educación, Vol. I. Psicología Evolutiva. Madrid: Alianza Psicología.

Padés Jiménez, A. (2003). Habilidades sociales en enfermería: Propuesta de un programa de intervención. Tesis doctoral. Universitat de les Illes Balears.

Pérez, E.; Mestre, M. V.; Samper, P.; Martí Vilar, M.; Fuentes, E.; Díez, I. i al. (1999). Intervención en el desarrollo personal y moral. Psicología Moral y Crecimiento Personal. Su situación en el cambio de siglo (pp. 191-210). Barcelona: Ariel.

Pérez, E.; Mestre, V.; Martí-Vilar, M.; Samper, P. (1996). Orígenes históricos del libro de J. Piaget «El juicio moral en el niño»: Sus fuentes filosóficas y científicas. Revista de Historia de la Psicología, 17(3-4), pp. 59-71.

Pool, C. R. (1997). Up with emotional health. Emotional Leadership, 54(8), pp. 12-14.

Rubin, K. H. i Rose-Krasnor, L. (1992). Interpersonal problem solving and social competence in children. En V. B. Van Hasselt i M. Hersen (Eds.), Handbook of Social Development (pp. 283 323). Nueva York: Plenum Press. 
Salter, A. (1949). Conditioned reflex therapy. Nueva York: Farrar, Strauss and Giroux.

Schaeffer, H. R. (1984). Interacción y socialización. Madrid: Visor.

Spence, S. H. i Liddle, B. (1990). Self-report measures of social competence for children: An evaluation of Social Skills for Youngsters and the List of Social Situation Problems. Behavioral Assessment, 12, pp. 317-336.

Stoudt, B. G. (2006). «You're either in or you're out»: School violence, peer discipline and the (re)production of hegemonic masculinity. Men and Masculinities, 8(3), pp. 273-287.

Topping, K.; Bremmer, W. i Holmes, E. A. (2000). Social Competence: The Social Construction of the Concept. En R. Bar-On i J. D. A. Parker, The Handbook of Emotional Intelligence. Theory, Development, Assessment, and Application at Home School, and in the Workplace. San Francisco, Ca: Jossey-Bass.

Wolpe, J. (1958). Psychotherapy by reciprocal inhibition. Palo Alto, California: Stanfoord University press.

Zaldívar Pérez, D. F. (1994). La Terapia Asertiva: una estrategia para su empleo. Revista Cubana de Psicología, 11(1), pp. 53-64.

Zuffianò, A.; Alessandri, G.; Luengo Kanacri, B. P.; Pastorelli, C.; Milioni, M.; Ceravolo, R.; Caprara, M. G. i Caprara, G. V. (2014). The relation between prosociality and self-esteem from middle-adolescence to young adulthood. Personality and Individual Differences, 63, pp. 24-29. doi: 10.1016/j. paid.2014.01.041.

Zuffianò, A.; Eisenberg, N.; Alessandri, G.; Luengo Kanacri, B.; Pastorelli, C.; Milioni, M. i Caprara, G. V. (2014). The Relation of Pro-Sociality to SelfEsteem: The Mediational Role of Quality of Friendships. Journal of Personality, 84(1), pp. 59-70. doi: 10.1111/jopy.12137.

Data de recepció: 16-06-2016

Data d'acceptació: 01-11-2016 